\title{
Novel 8-hydroxylquinoline analogs induce copper-dependent proteasome inhibition and cell death in human breast cancer cells
}

\author{
VESNA MILACIC ${ }^{1}$, PEIFU JIAO ${ }^{2}$, BIN ZHANG $^{2}$, BING YAN $^{2,3}$ and Q. PING DOU ${ }^{1}$ \\ ${ }^{1}$ The Prevention Program, Barbara Ann Karmanos Cancer Institute, and Department of Pathology, School of Medicine, \\ Wayne State University, Detroit, MI, USA; ${ }^{2}$ School of Pharmaceutical Sciences, Shandong University, Jinan, \\ Shandong, P.R. China; ${ }^{3}$ St. Jude Children's Research Hospital, Memphis, TN, USA
}

Received May 14, 2009; Accepted July 7, 2009

DOI: 10.3892/ijo_00000467

\begin{abstract}
An elevated level of copper $(\mathrm{Cu})$, which is necessary for the growth and metastasis of tumor cells, has been found in many types of cancer, including breast, prostate, lung and brain. Although its molecular basis is unclear, this tumor-specific $\mathrm{Cu}$ elevation has been proposed to be a novel target for developing selective anti-cancer therapies. We previously reported that 8-hydroxylquinoline (8-OHQ) is able to form a $\mathrm{Cu}$ complex that inhibits the proteasome and induces apoptosis in cultured cancer cells. Toward the goal of discovering novel 8-OHQ analogs as potential anti-copper and anti-cancer drugs, in the current study we synthesized several 8-OHQ analogs and their copper complexes and evaluated their biological activities in human breast cancer cells. We report that when substitutions are made on the hydroxyl group of 8-OHQ, their copper mixtures have profound effects on the proteasome-inhibitory and apoptosis-inducing abilities in breast cancer MDA-MB-231 cells. In addition, the proteasome-inhibitory and apoptosis-inducing activities of 8-OHQ analog-copper mixtures are determined by both the polarity and position of the substituents. Finally, a synthetic complex of 8-OHQ analog-copper was able to inhibit the proteasome activity, induce cell death and suppress the growth selectively in breast cancer MDA-MB-231 cells, but not in normal immortalized human breast MCF-10A cells. Our results support the concept that human cancer cells and tissues,
\end{abstract}

Correspondence to: Dr Q. Ping Dou, The Prevention Program, Barbara Ann Karmanos Cancer Institute, Department of Pathology, Wayne State University School of Medicine, 540.1 HWCRC, 4100 John R Rd, Detroit, MI 48201-2013, USA

E-mail: doup@karmanos.org

Dr Bing Yan, Department of Chemical Biology and Therapeutics, St. Jude Children's Research Hospital, 332 North Lauderdale Street, Memphis, TN 38105, USA

E-mail: bing.yan@stjude.org

Key words: 8-hydroxylquinoline, copper, anti-copper drugs, structure activity relationship, proteasome inhibitors, apoptosis which contain an elevated copper level and are highly dependent on proteasome activity for their survival, should be sensitive to treatment with anti-copper drugs such as the novel 8-OHQ analogs described here.

\section{Introduction}

Copper is a trace element essential for various metabolic processes in living organisms $(1,2)$. It plays a central role in conserved processes, such as respiration, and in highly specialized processes, such as protein modifications. Since copper has the ability to adopt both oxidized $\left(\mathrm{Cu}^{2+}\right)$ and reduced $\left(\mathrm{Cu}^{+}\right)$states, it is also a crucial redox cofactor for $\mathrm{Cu}$-dependent oxidases (1). Having these important physiologic functions, it is not surprising that the concentration of copper in organisms is tightly regulated $(1,3)$.

However, an elevated copper level has been found in many types of cancer, including breast, prostate, lung and brain (4-7). For example, it has been reported that the copper level reaches $167.3 \mu \mathrm{g} / 100 \mathrm{ml}$ in the serum of breast cancer patients, compared to $98.8 \mu \mathrm{g} / 100 \mathrm{ml}$ in the serum of healthy controls (8). Although the detailed molecular mechanisms for tumorassociated copper elevation are not completely clear, this accumulation could be explained, at least partly, by the vital role copper plays in angiogenesis, a process critical for tumor growth. Many groups have shown that angiogenesis requires copper as a crucial cofactor that stimulates cytokine production, extracellular matrix degradation, endothelial cell proliferation and migration mediated by integrins (9-11). It has been hypothesized that an elevated copper level can be tumor-specific and therefore can be targeted by newly developed anti-cancer therapeutics (12). Based on these important facts, the possibility to control tumor growth, angiogenesis, and metastasis by chelating copper has been explored. In an attempt to do so, small molecules with copper-binding ability that are easily synthesized and structurally manipulated, have become an attractive tool.

The ubiquitin-proteasome pathway is essential for many fundamental cellular processes, including the cell cycle, apoptosis, angiogenesis and differentiation $(13,14)$. This pathway contributes to the pathological states of several human diseases including AIDS and cancer, in which some 
regulatory proteins are either stabilized due to decreased degradation or lost due to accelerated degradation (15). The $20 \mathrm{~S}$ proteasome, the proteolytic core of the $26 \mathrm{~S}$ proteasome complex, contains multiple peptidase activities, including the chymotrypsin (CT)-like, trypsin-like and peptidylglutamyl peptide hydrolyzing (PGPH)-like activities (16). It has been shown that inhibition of the CT-like but not other proteasomal activities is a strong stimulus that induces apoptosis $(17,18)$.

Along this line, proteasome inhibitors are proposed to have potential as new anti-cancer drugs. These inhibitors could block proteasome function with little effect on other normal biological processes in the cell. The fact that cancer cells are more sensitive to proteasome inhibitors than normal or untransformed cells makes proteasome inhibitors even more attractive (19-21).

Due to their anti-microbial, anti-pyretic, anti-inflammatory, and anti-cancer properties, heterocyclic compounds have been widely investigated in drug discovery and development. We previously reported that one member of this family, 8hydroxylquinoline (8-OHQ) is able to form a copper complex that inhibits proteasome activity, resulting in proliferation suppression and apoptosis induction in cultured breast and prostate cancer cells $(22,23)$.

Toward the goal of discovering novel 8-OHQ analogs as potential anti-cancer drugs, in the current study we synthesized several 8-OHQ analogs and their copper complexes and evaluated their biological activities. We revealed that when substitutions are made on the hydroxyl group of 8-OHQ, their copper mixtures have profound effects on the proteasomeinhibitory and apoptosis-inducing abilities in cultured human breast cancer cells. We also showed that the activity of 8-OHQ analog-copper mixtures is determined by the polarity and position of the substituents. Finally, one of the synthetic complexes of 8-OHQ analog-copper, $\mathrm{S} 13-\mathrm{Cu}$, discriminated between human breast cancer and non-cancer cells, showing a potential for selective anti-cancer treatment.

\section{Materials and methods}

Synthesis of novel 8-OHQ analogs and their copper complexes. 8-OHQ analogs, compounds \#10-\#16 (Fig. 1A), were synthesized as described below. 8-Hydroxylquinoline (8-OHQ) (0.15 g, $1 \mathrm{mmol})$ was dissolved in absolute tetrahydrofuran (THF) (15 ml), followed by addition of solid $\mathrm{K}_{2} \mathrm{CO}_{3}(0.14 \mathrm{~g}, 1 \mathrm{mmol})$. After refluxing for $0.5 \mathrm{~h}$, a THF solution containing substituted-N-phenylacetamide $(0.17 \mathrm{~g}$, $1 \mathrm{mmol}$ ) was added. The reaction mixture was stirred at the refluxing temperature for $72 \mathrm{~h}$. After cooling to room temperature, the reaction mixture was worked up by filtration. The filtrate was concentrated in a vacuum to remove THF. The resulting mixture was purified by silica gel column chromatography and eluted with EtOAc and petroleum ether to obtain 0.1-0.2 g of products. The 8-OHQ analog-copper crystals (S10-Cu, S13-Cu, S16-Cu) were made according to the following procedure. To a solution of 8-hydroxylquinoline analogs $(1 \mathrm{mmol})$ in absolute methanol $(20 \mathrm{ml})$, an equivalent amount of $\mathrm{CuCl}_{2} \cdot \mathrm{H}_{2} \mathrm{O}(1 \mathrm{mmol})$ in absolute methanol $(10 \mathrm{ml})$ was added dropwise with constant stirring. The mixture was continuously stirred for $24 \mathrm{~h}$. The crystallized copper complex was filtered, washed with absolute methanol, and then dried in a vacuum. The detailed procedure of synthesis of these compounds will be published elsewhere (Jiao et al).

Materials. 8-OHQ, copper chloride, dimethylsulfoxide (DMSO), sodium bicarbonate and 3-[4,5-dimethyltiazol-2yl]-2.5-diphenyl-tetrazolium bromide (MTT) were purchased from Sigma-Aldrich (St. Louis, MO, USA). DMEM/F12 (1:1), HEPES, fetal bovine serum, horse serum, cholera toxin, hydrocortisone, epidermal growth factor, insulin, penicillin and streptomycin were purchased from Invitrogen (Carlsbad, CA). Purified rabbit 20S proteasome and fluorogenic peptide substrate Suc-LLVY-AMC (for the proteasomal CT-like activity) was from Calbiochem (San Diego, CA, USA). Mouse monoclonal antibody against human poly(ADP-ribose) polymerase (PARP) was purchased from BioMol International LP (Plymouth Meeting, PA). Mouse monoclonal antibodies against Bax (B-9), ubiquitin (P4D1), rabbit polyclonal antibody against $\mathrm{I} \kappa \mathrm{B}-\alpha(\mathrm{C}-15)$, goat polyclonal antibody against actin (C-11), and secondary antibodies were from Santa Cruz Biotechnology, Inc. (Santa Cruz, CA).

Cell cultures and whole cell extract preparation. Highly metastatic and malignant human breast cancer MDA-MB-231 cells were grown in DMEM/F12 supplemented with $10 \%$ (v/v) fetal bovine serum, 100 units/ml of penicillin, and $100 \mu \mathrm{g} /$ $\mathrm{ml}$ of streptomycin, at $37^{\circ} \mathrm{C}$ in a humidified incubator with an atmosphere of $5 \% \mathrm{CO}_{2}$. Immortalized human breast epithelial MCF-10A cells were cultured in DMEM/F12 medium supplemented with $5 \%(\mathrm{v} / \mathrm{v})$ horse serum, 100 units $/ \mathrm{ml}$ of penicillin, $100 \mu \mathrm{g} / \mathrm{ml}$ of streptomycin, $52.55 \mu \mathrm{g}$ of cholera endotoxin, $5 \mathrm{mg}$ insulin, $10 \mathrm{ml}$ of $1 \mathrm{M} \mathrm{NaHCO}_{3}, 10 \mu \mathrm{g}$ of epidermal growth factor, and $250 \mu \mathrm{g}$ hydrocortisone. A whole cell extract was prepared as previously described (17). Briefly, cells were washed twice with PBS and homogenized in a lysis buffer [50 mM Tris ( $\mathrm{pH} 8.0), 150 \mathrm{mM} \mathrm{NaCl}, 0.5 \%$ $\mathrm{NP} 40]$. After $20 \mathrm{~min}$ of rocking at $4^{\circ} \mathrm{C}$, the mixtures were centrifuged at $12,000 \mathrm{~g}$ for $15 \mathrm{~min}$, and the supernatants were collected as whole cell extracts.

Western blot analysis. Breast cancer MDA-MB-231 cells were treated as indicated in the figure legends. Cell lysates $(50 \mu \mathrm{g})$ were separated by SDS-PAGE and transferred to a nitrocellulose membrane, followed by visualization using the enhanced chemiluminescence kit (Amersham Biosciences, Piscataway, NJ) as previously described (24).

Proteasome activity assay using whole cell extracts. MDAMB-231 cells were grown to 70-80\% confluency, treated under various conditions, harvested, and used for whole cell extract preparation. The cell extract $(8 \mu \mathrm{g})$ was then used to determine the proteasomal chymotrypsin-like activity, as previously described (25).

Inhibition of the proteasomal chymotrypsin-like activity in intact cells. MDA-MB-231 and MCF-10A cells were grown to $70-80 \%$ confluency and treated under various conditions. After the additional 2-h incubation with the fluorogenic peptide substrate Suc-LLVY-AMC, specific for the 


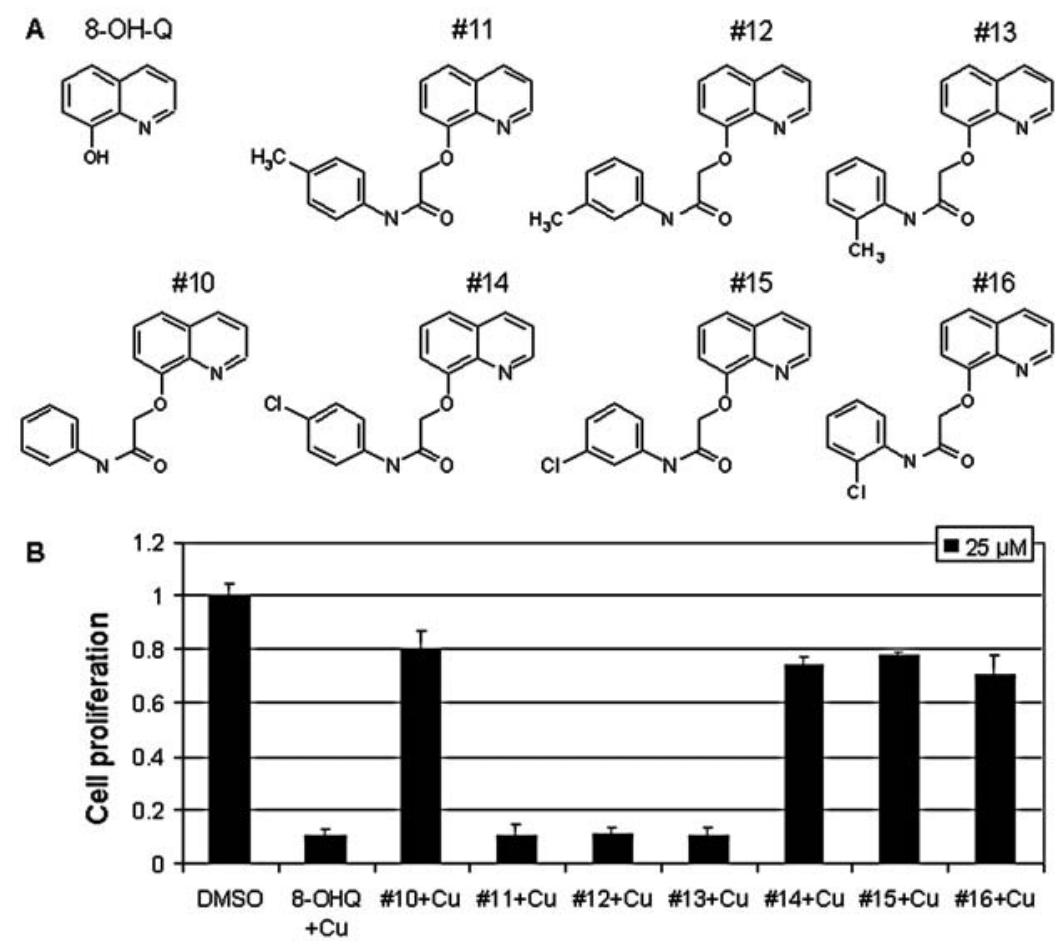

C

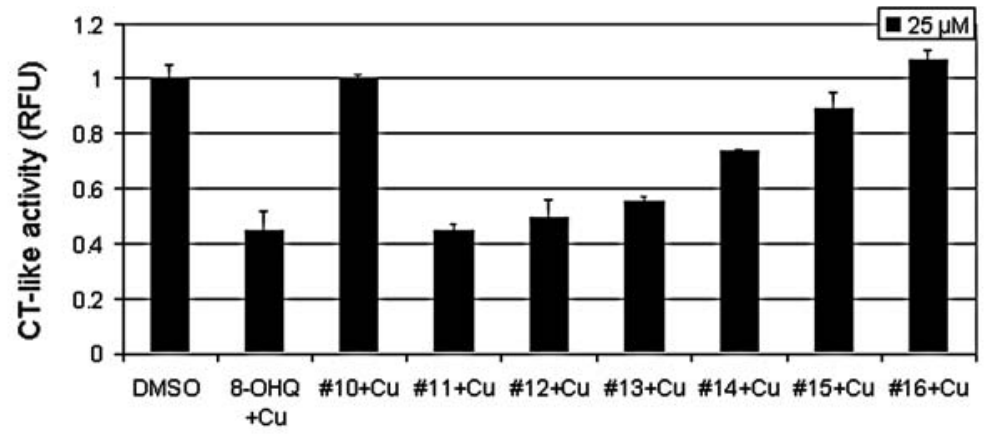

Figure 1. Copper mixtures with 8-OHQ analogs inhibit proliferation and proteasomal chymotrypsin-like (CT-like) activity in breast cancer MDA-MB-231 cells. (A) Chemical structures of 8-hydroxylquinoline (8-OHQ) and seven 8-OHQ analogs. (B) Anti-proliferative effect of copper mixtures with different 8-OHQ analogs. MDA-MB-231 cells were treated for $24 \mathrm{~h}$ with copper mixtures of different analogs at $25 \mu \mathrm{M}$, followed by MTT assay as described in Materials and methods. (C) Inhibition of proteasomal CT-like activity in intact MDA-MB-231 cells. MDA-MB-231 cells were treated with different 8-OHQ analog-copper mixtures at $25 \mu \mathrm{M}$ for $24 \mathrm{~h}$, followed by measurement of proteasomal CT-like activity. Copper mixture with 8-OHQ was used as a positive control and DMSO was used as a solvent control.

proteasomal CT-like activity $(20 \mu \mathrm{M})$, production of hydrolyzed AMC groups was measured, as described above.

Cell proliferation assay. The MTT assay was used to determine the effects of various compounds on proliferation of MDA-MB-231 and MCF-10A cells. Cells were plated in a 96-well plate and grown to $70-80 \%$ confluency, followed by addition of each compound at the indicated concentrations. After a $24 \mathrm{~h}$ incubation at $37^{\circ} \mathrm{C}$, inhibition of cell proliferation was measured as previously described (25).

Analysis of cellular morphology. A Zeiss (Thornwood, NY) Axiovert 25 microscope with phase contrast was used for cellular morphology imaging, as previously described (22).

\section{Results}

Mixtures of novel 8-OHQ analogs and copper inhibit MDA$M B-231$ cell proliferation. We previously showed that 8-OHQ mixed with copper forms a complex that has a potential to inhibit the proteasome and induce apoptosis in human leukemia Jurkat T cells (26). In the current study, we attempted to search for novel 8-OHQ analogs toward discovery of novel anti-copper and anti-cancer drugs. As the first step, we synthesized seven new 8-OHQ analogs, \#10-\#16 (Fig. 1A). In analog \#10, the hydroxyl group of 8-OHQ was substituted with $\mathrm{N}$-phenylacetamide at the 2-position. In analogs \#11, $\# 12$ and \#13, a single methyl group was attached to the phenyl ring on the $\mathrm{N}$-phenylacetamide substituent at different positions, while in analogs \#14, \#15 and \#16 a chlorine was attached to the phenyl ring at different positions (Fig. 1A).

Cultured cancer cells, unlike in vivo situations, have low to trace levels of copper (26). Therefore, we treated cultured human breast cancer MDA-MB-231 cells with mixtures (at $25 \mu \mathrm{M}$ concentration) prepared by mixing solutions of each 8-OHQ analog and copper chloride at a 1:1 ratio (vol:vol) and measured their anti-proliferative effect by an MTT assay. In this experiment, the 8-OHQ-Cu mixture was used as a 
A

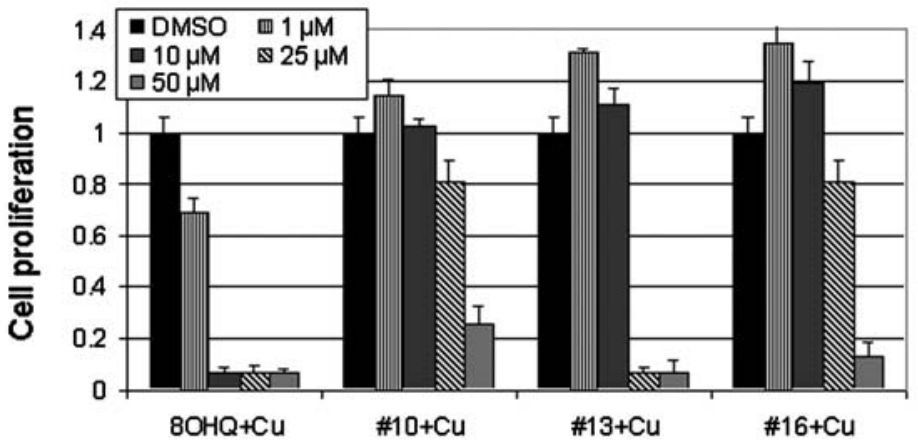

B

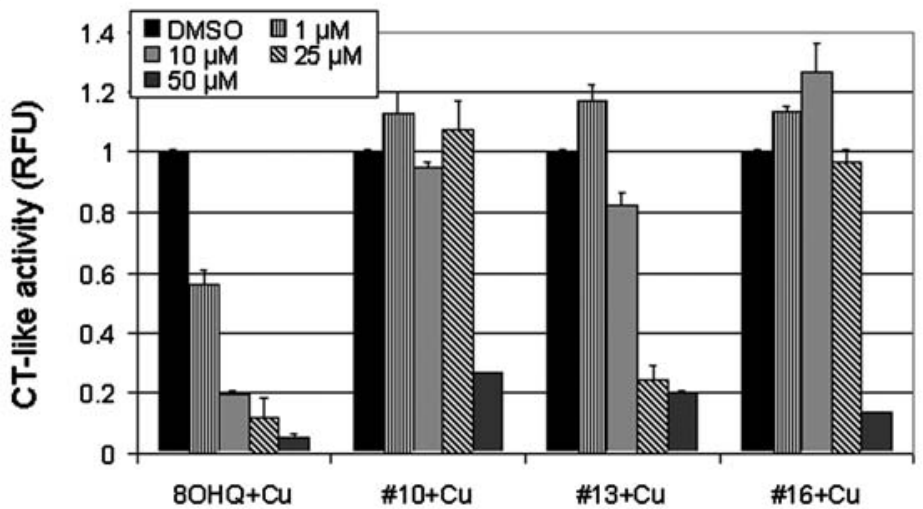

Figure 2. Copper mixtures with 8-OHQ analogs inhibit proliferation and proteasomal chymotrypsin (CT)-like activity in MDA-MB-231 cells in a dosedependent manner. (A) MDA-MB-231 cells were treated with copper mixtures of 8-OHQ analogs \#10, \#13 and \#16 for $24 \mathrm{~h}$, followed by MTT assay. (B) MDA-MB-231 cells were treated with copper mixtures of 8-OHQ analogs \#10, \#13 and \#16, as indicated. After $24 \mathrm{~h}$, fluorogenic substrate Suc-LLVYAMC, specific for the proteasomal CT-like activity (at $20 \mu \mathrm{M}$ ) was added as described in Materials and methods. Copper mixture with 8-OHQ was used as a positive control and DMSO was used as a solvent control.

positive control. We found that the copper-containing mixtures of 8 -OHQ analogs \#11, \#12, and \#13 at $25 \mu \mathrm{M}$ inhibited $\sim 90 \%$ of MDA-MB-231 cell proliferation, similar to the 8-OHQ-Cu mixture (Fig. 1B). Copper mixtures with analogs \#10, \#14, \#15 and \#16 had only a minor antiproliferative effect by inducing 20-30\% inhibition (Fig. 1B), suggesting that attachment of a methyl group, but not chlorine, to the phenyl ring of the N-phenylacetamide substituent does not affect the growth-inhibitory activity of the copper complex.

To investigate whether the anti-proliferative effect of these mixtures is coupled with their ability to inhibit cellular $26 \mathrm{~S}$ proteasome, in a similar experiment we treated MDAMB-231 cells with $25 \mu \mathrm{M}$ of each mixture for $24 \mathrm{~h}$, followed by measurement of proteasomal CT-like activity. We found $45-55 \%$ of proteasomal inhibition only in the cells treated with copper mixtures with analogs \#11, \#12, and \#13 (Fig. 1C), while copper mixtures with analogs \#10, \#14, \#15, and \#16 had only minor effects on the proteasomal activity (Fig. 1C). Therefore, the ability of 8-OHQ analogs mixed with copper to inhibit MDA-MB-231 cell proliferation correlates with their ability to inhibit cellular 26S proteasome. These data suggest that attachment of a methyl group, but not chlorine, to the phenyl ring of the N-phenylacetamide substituent does not affect the proteasome-inhibitory activity of the copper mixture (see Discussion)

Analog \#13-copper mixture inhibits MDA-MB-231 cell proliferation and proteasome activity and induces apoptosis in a dose-dependent manner. To further study the effect and structure-activity relationships (SAR) of 8-OHQ analogs, we selected one of the potent analogs (\#13) and two analogs with lower potency (\#10 and \#16). By using an MTT assay, we first tested whether the anti-proliferative effects of their copper mixtures are concentration-dependent. We found that at 1 - and $10 \mu \mathrm{M}$ concentrations, all three mixtures somewhat stimulated proliferation of MDA-MB-231 cells (Fig. 2A). However, at $25 \mu \mathrm{M}$, the \#13-Cu mixture induced 94\% inhibition, while copper mixtures of \#10 and \#16 inhibited only $20 \%$ of MDA-MB-231 cell proliferation (Fig. 2A). When used at a $50 \mu \mathrm{M}$ concentration, the analog \#13-copper mixture was again the most potent, inhibiting almost $95 \%$ of cell proliferation, while the \#10-Cu and \#16-Cu mixtures induced 77 and 86\%, respectively (Fig. 2A).

To investigate whether the proteasome-inhibitory effect of the \#10-Cu, \#13-Cu, and \#16-Cu mixtures is also concentrationdependent, we plated MDA-MB-231 cells in a 96-well plate and treated them with these three mixtures at the same concentrations $(1,10,25$ and $50 \mu \mathrm{M})$. The $24 \mathrm{~h}$ treatment was followed by $2 \mathrm{~h}$ of additional incubation with a specific peptide substrate for the proteasomal CT-like activity. We found that indeed, all three mixtures inhibited the cellular proteasomal CT-like activity in a dose-dependent manner (Fig. 2B). At $10 \mu \mathrm{M}$, the \#13-Cu mixture inhibited $20 \%$ of the proteasomal activity, while at concentrations of 25 and $50 \mu \mathrm{M}$ it induced almost $80 \%$ inhibition (Fig. 2B). Similarly to their anti-proliferative effect, when used at 1-25 $\mu \mathrm{M}$, mixtures of \#10 and \#16 with copper did not have any effect 


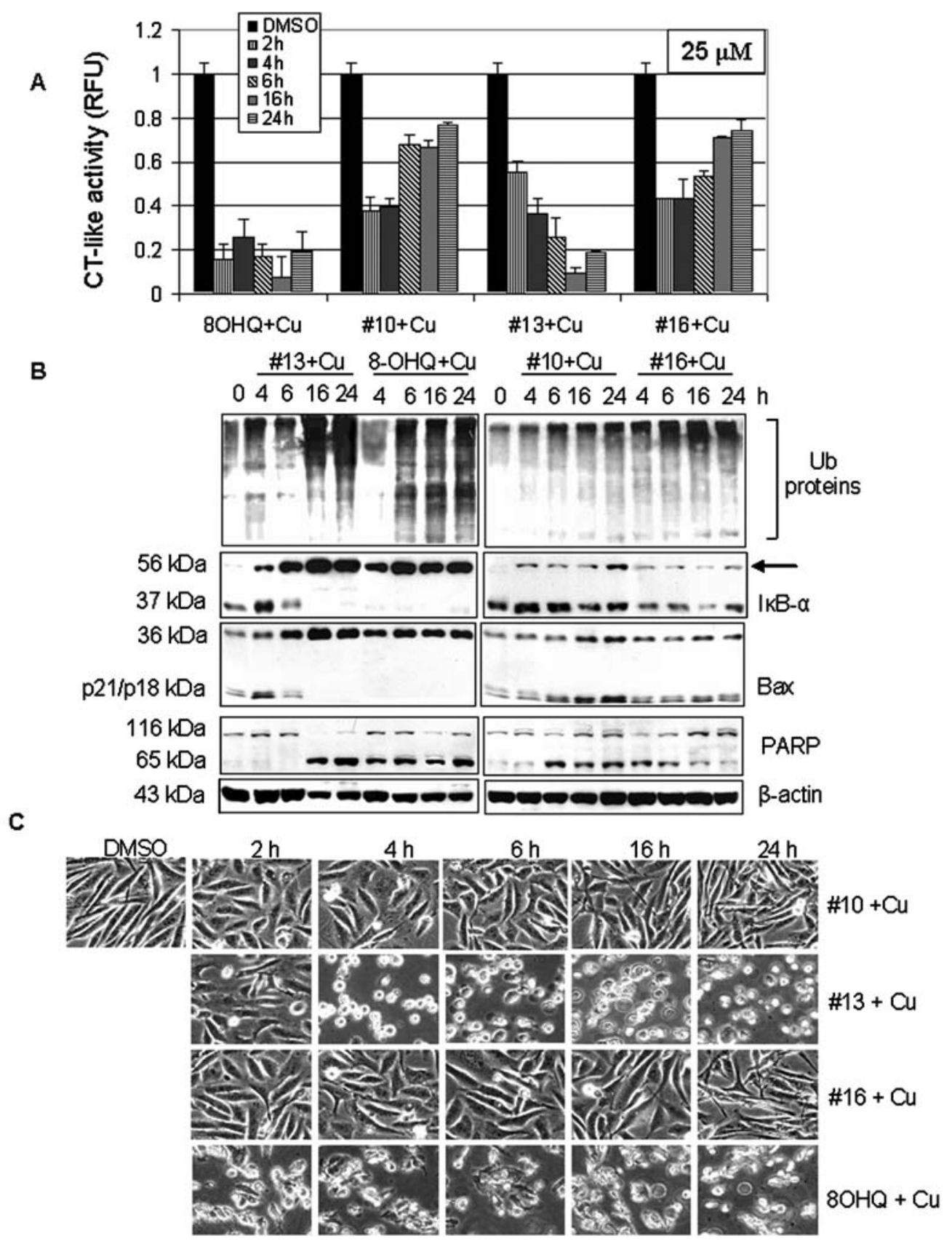

Figure 3. Kinetic studies of the proteasome inhibition and apoptosis induction by the \#10-Cu, \#13-Cu, and \#16-Cu mixtures. MDA-MB-231 cells treated with $25 \mu \mathrm{M}$ of the copper mixtures of 8-OHQ analogs \#10, \#13 or \#16 for the indicated times were used for whole cell extract preparation. Cell extracts were used for measurement of the proteasomal chymotrypsin (CT)-like activity (A), Western blot analysis using specific antibodies to ubiquitin, IкB- $\alpha$ (arrow, ubiquitinated form of IкB- $\alpha$ ), Bax, PARP, and $\beta$-actin (B), and apoptotic morphological changes visualized by phase-contrast imaging (C).

on the proteasomal activity; however, when used at $50 \mu \mathrm{M}$, they induced 73 and $85 \%$ inhibition, respectively (Fig. 2B).

To further confirm the proteasomal inhibition caused by these 8-OHQ analog-Cu mixtures, MDA-MB-231 cells were treated with $25 \mu \mathrm{M}$ of each of the \#10-Cu, \#13-Cu, \#16-Cu and 8-OHQ- $\mathrm{Cu}$ (as a control) mixtures for up to $24 \mathrm{~h}$, followed by performance of multiple assays. We first measured proteasomal activity levels in the prepared cell extracts using a cell-free activity assay and found a time-dependent proteasomal inhibition induced by the \#13-Cu mixture (Fig. 3A). Although mixtures \#10-Cu and \#16-Cu inhibited $20 \%$ of the proteasomal activity in the first $4 \mathrm{~h}$ of treatment, after $6 \mathrm{~h}$ proteasomal activity recovered toward the end of the treatment (Fig. 3A). Western blot analysis confirmed the protea- somal inhibition induced by the \#13-Cu mixture, since it showed accumulation of ubiquitinated proteins and proteasomal target protein IкB- $\alpha$ at $4 \mathrm{~h}$ (Fig. 3B). We previously reported a ubiquitinated form of the IкB- $\alpha$ protein with a molecular weight of $\sim 56 \mathrm{kDa}$ (23). Similar p56 bands were detected after 4-24 h of treatment with mixtures of \#13 and 8-OHQ with copper (Fig. 3B). Consistently with the slight inhibition of the proteasomal activity, some accumulation of ubiqui-tinated proteins and ubiquitinated IкB- $\alpha$ protein was also detected after \#10-Cu and \#16-Cu treatments (Fig. 3B).

In the same experiment, characteristic apoptotic morphological changes (shrunken cells and blebbing) were detected mainly in the cells treated with the \#13-Cu and 8-OHQ- $\mathrm{Cu}$ mixtures starting from 4 and $2 \mathrm{~h}$, respectively 


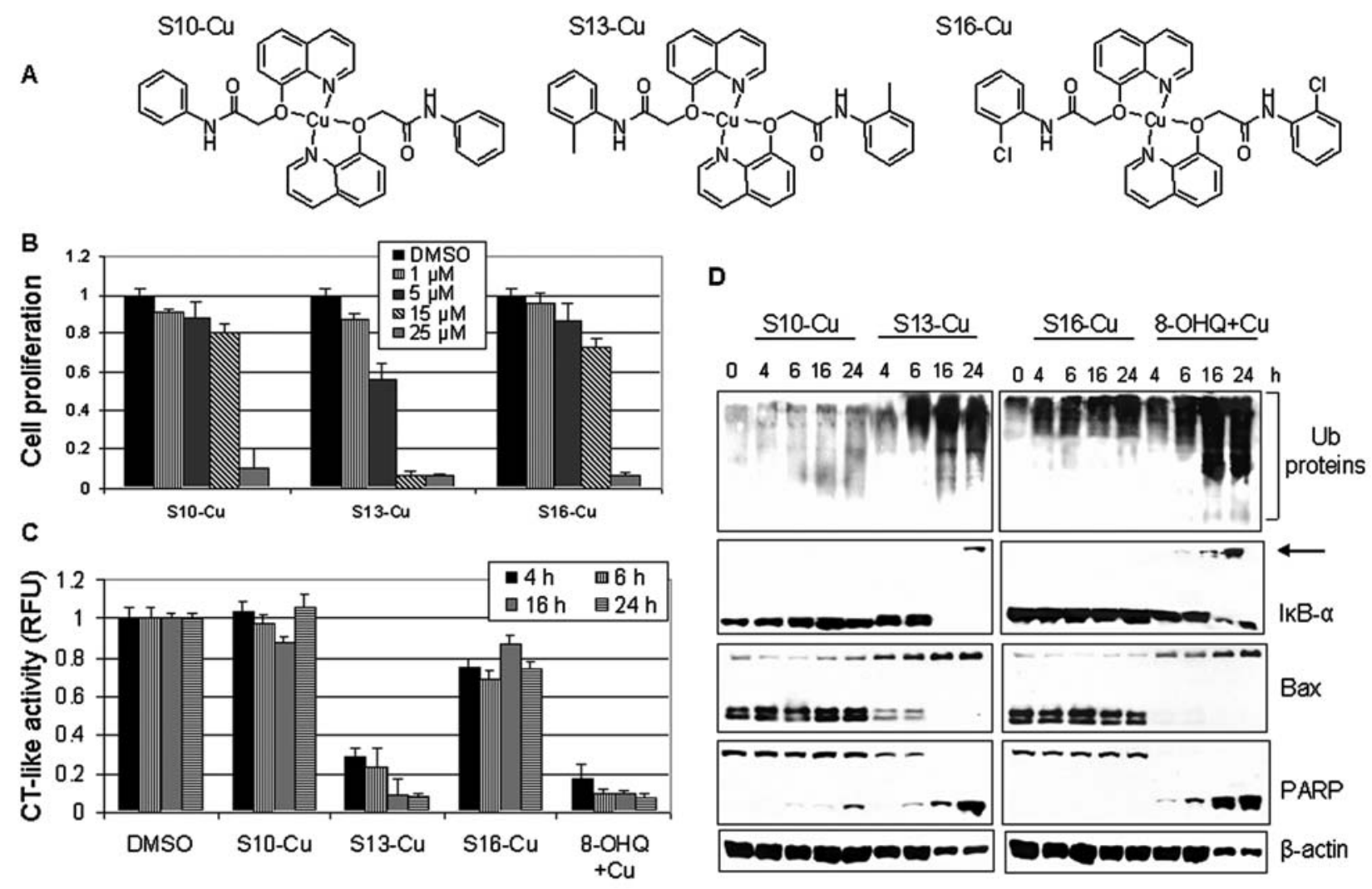

Figure 4. Effect of synthetic compounds, S10-Cu, S13-Cu and S16-Cu, on MDA-MB-231 cells. (A) Chemical structures of synthetic compounds S10-Cu, S13-Cu and S16-Cu. (B) MDA-MB-231 cells were treated with synthetic compounds S10-Cu, S13-Cu and S16-Cu for $24 \mathrm{~h}$ as indicated, followed by MTT assay. Copper mixture with 8-OHQ was used as a positive control and DMSO was used as a solvent control. (C and D) MDA-MB-231 cells treated with $15 \mu \mathrm{M}$ synthetic compounds $\mathrm{S} 10-\mathrm{Cu}, \mathrm{S} 13-\mathrm{Cu}$ and $\mathrm{S} 16-\mathrm{Cu}$ for indicated times were harvested and lysed. Cell extract was used for measurement of the proteasomal chymotrypsin (CT)-like activity (C) and Western blot analysis using specific antibodies to ubiquitin, IкB- $\alpha$, Bax, PARP, and B-actin (D). Arrow, ubiquitinated form of IкB- $\alpha$ (D).

(Fig. 3C). Treatment with the \#10-Cu and \#16-Cu mixtures for even $24 \mathrm{~h}$ did not induce much morphological change (Fig. 3C). Associated with the morphological changes, production of cell death-related PARP cleaved fragment p65 was also detected in the cells with the rank: \#13-Cu, 8-OHQ$\mathrm{Cu}>\# 10-\mathrm{Cu}>\# 16-\mathrm{Cu}$ (Fig. 3B). Detection of the PARP p65 fragment suggested activation of calpain since it has been shown that calpain is able to cleave PARP into a fragment of $\sim 65 \mathrm{kDa}$ (27).

We and others have shown that associated with the apoptotic commitment, Bax protein ( $\mathrm{p} 21 / \mathrm{Bax}$ ) is able to be cleaved by calpain, producing a p18/Bax fragment, which then forms a homodimer p36/Bax $(28,29)$. Although we observed some accumulation of $\mathrm{p} 36 / \mathrm{Bax}$ protein in the cells treated with the \#10-Cu and \#16-Cu mixtures (Fig. 3B), a complete disappearance of $\mathrm{p} 21 / \mathrm{Bax}$ and $\mathrm{p} 18 / \mathrm{Bax}$ together with the vast accumulation of p36/Bax was observed mainly after treatment with \#13-Cu and 8-OHQ-Cu (Fig. 3B).

Effect of synthetic 8-OHQ analog-copper complexes. To confirm the results obtained with the mixtures of the 8-OHQ analogs and copper (Figs. 1-3), we synthesized complexes \#10-Cu (S10-Cu), \#13-Cu (S13-Cu) and \#16-Cu (S16-Cu), each with the 8-OHQ analog:copper molar ratio 2:1 (Fig. 4A). We first tested their anti-proliferative potencies by MTT assay and found that similarly to their copper mixtures, synthetic compound $\mathrm{S} 13-\mathrm{Cu}$ was more potent than $\mathrm{S} 10-\mathrm{Cu}$ and $\mathrm{S} 16-\mathrm{Cu}$.
At $5 \mu \mathrm{M}, \mathrm{S} 13-\mathrm{Cu}$ caused $45 \%$ inhibition, while both $\mathrm{S} 10-\mathrm{Cu}$ and S16-Cu inhibited only $10 \%$ of MDA-MB-231 cell proliferation (Fig. 4B). When used at a $15 \mu \mathrm{M}$ concentration, $\mathrm{S} 13-\mathrm{Cu}$ induced $>90 \%$ inhibition, while $\mathrm{S} 10-\mathrm{Cu}$ and $\mathrm{S} 16-\mathrm{Cu}$ inhibited only $\sim 20$ and 30\% of MDA-MB-231 cell proliferation, respectively (Fig. 4B). However, when used at $25 \mu \mathrm{M}$ concentrations, $\mathrm{S} 16-\mathrm{Cu}$ and $\mathrm{S} 10-\mathrm{Cu}$ were almost as potent as S13-Cu since they inhibited 90, 93 and $93 \%$, respectively (Fig. 4B).

We next investigated the potency of these three synthetic complexes to inhibit the purified 20S proteasome and found that even at the highest concentration used $(25 \mu \mathrm{M})$, all three complexes inhibited only $20 \%$ of the proteasomal CT-like activity (data not shown). Although these complexes showed only minor inhibitory activity against the purified $20 \mathrm{~S}$ proteasome, they were found to be much more potent against the cellular 26S proteasome. After we treated MDA-MB-231 cells with all three complexes at a $15 \mu \mathrm{M}$ concentration, we found that $\mathrm{S} 13-\mathrm{Cu}$ inhibited $>70$ and $90 \%$ of the proteasomal CT-like activity after 4 and $24 \mathrm{~h}$ of treatment, respectively (Fig. 4C), In contrast, S16-Cu only caused $\sim 20 \%$ inhibition of the proteasome activity during the treatment period, and S10-Cu had a very slight inhibitory effect (Fig. 4C).

Proteasomal inhibition was confirmed by Western blot analysis which showed an accumulation of ubiquitinated proteins by treatment of the S13-Cu and 8-OHQ-copper mixture (as a positive control) for 6 to $24 \mathrm{~h}$ (Fig. 4D). In 

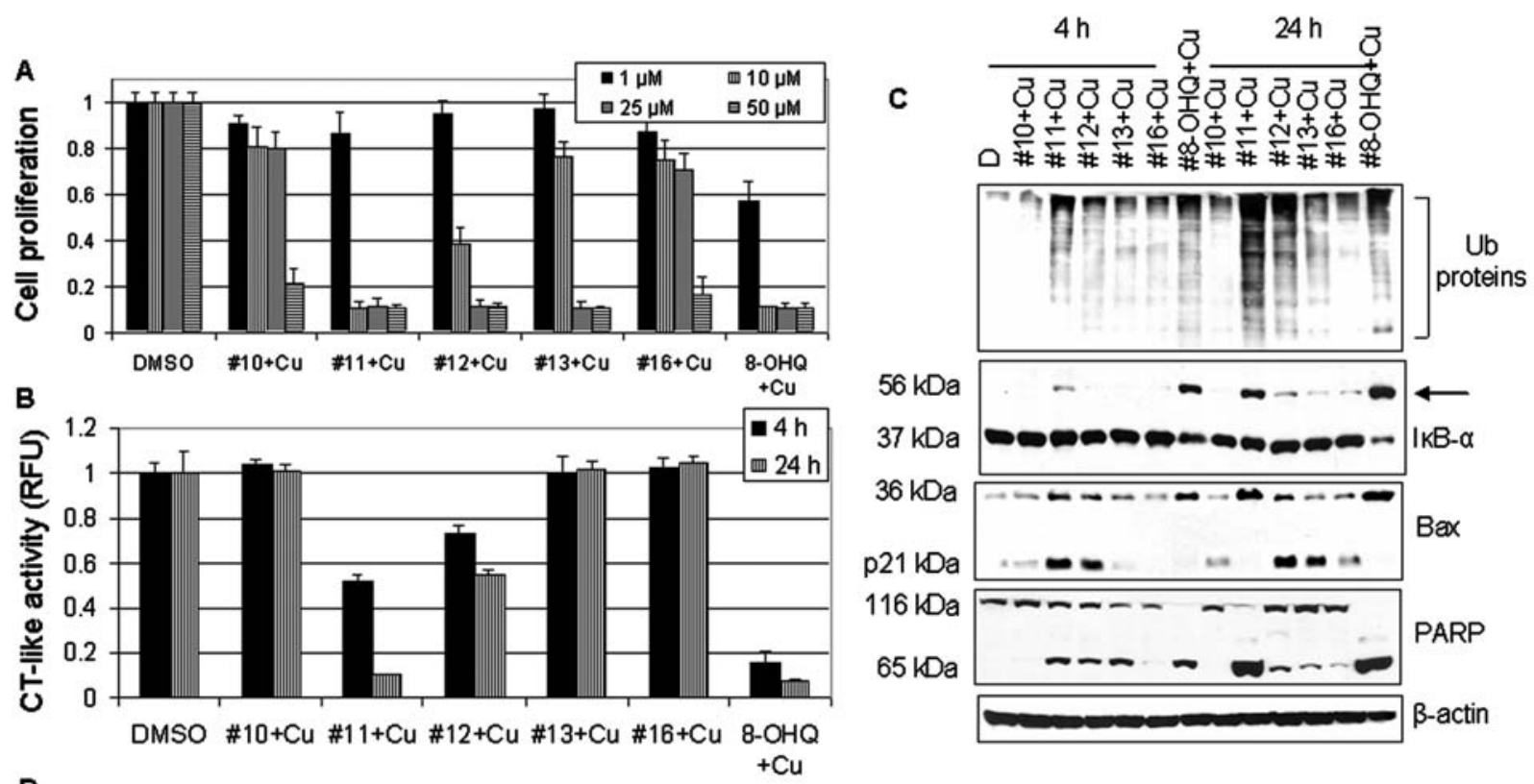

D
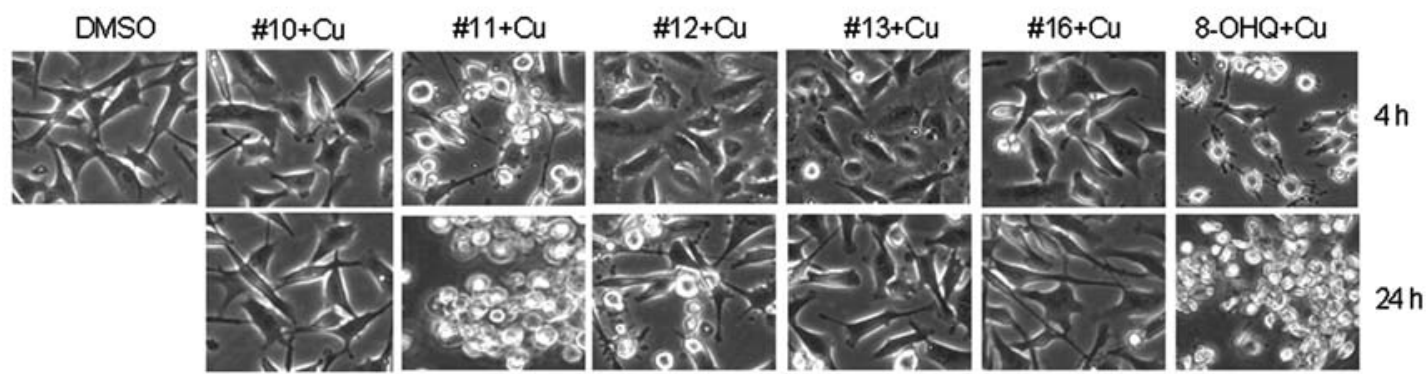

Figure 5. Structure-activity relationship (SAR) studies of the copper mixtures with 8-OHQ analogs \#11, \#12 and \#13. (A) MDA-MB-231 cells were treated with $10 \mu \mathrm{M}$ of the copper mixtures of 8-OHQ analogs \#11, \#12 or \#13 for $24 \mathrm{~h}$, followed by MTT assay. The copper mixtures with 8-OHQ and its analogs \#10 and \#16 were used as controls. DMSO was used as a solvent control. (B) MDA-MB-231 cells treated as indicated were harvested and lysed. Cell extracts were then used for measurement of the proteasomal chymotrypsin (CT)-like activity (B), Western blot analysis using specific antibodies to ubiquitin, IкB$\alpha$, Bax, PARP and B-actin (C), and assessment of apoptotic morphological changes in the MDA-MB-231 cells, visualized by phase-contrast imaging (D).

contrast, S10-Cu and S16-Cu had much less effect (Fig. 4D). Consistently, the ubiquitinated form of the proteasomal target protein IкB- $\alpha$ was observed only in the cells treated with synthetic $\mathrm{S} 13-\mathrm{Cu}$ (at $24 \mathrm{~h}$ ) and the 8-OHQ-copper mixture (at 16 and $24 \mathrm{~h}$ ), but not with S10-Cu and S16-Cu (Fig. 4D). In the same cells, accumulation of p36 Bax and complete disappearance of p21 and p18 Bax were detected mainly in the cells treated with synthetic $\mathrm{S} 13-\mathrm{Cu}$ and the $8-\mathrm{OHQ}-\mathrm{Cu}$ mixture (Fig. 4D).

To investigate whether the proteasomal inhibition by $\mathrm{S} 13-\mathrm{Cu}$ is associated with induction of apoptosis, morphological changes and PARP cleavage were studied. Synthetic complex S13-Cu caused considerable apoptosis-associated morphological changes (shrunken cells and blebbing), while $\mathrm{S} 10-\mathrm{Cu}$ and S16-Cu had only a minor effect (data not shown), very similar to that obtained with the corresponding copper mixtures (see Fig. 3C). Morphological changes induced by $\mathrm{S} 13-\mathrm{Cu}$ and the 8-OHQ-copper mixture were accompanied by PARP cleavage and appearance of the p65 cleaved PARP fragment (Fig. 4D).

Relationship of the position of the methyl group in analogs \#11, \#12 and \#13 with their biological activities. We demonstrated that the presence of a methyl group on the phenyl ring in the N-phenylacetamide substituent is important for the proteasome-inhibitory potency of 8-OHQ analogs \#11, \#12 and \#13, compared to \#10 (Figs. 1-3). To investigate whether the position of the methyl group on the N-phenylacetamide affects its biological activity, we further studied all the three analogs with a methyl group at the para (\#11), meta (\#12) and ortho position (\#13) (Fig. 1A). We first performed MTT assay and found that copper-containing mixtures of analogs $\# 11$, \#12, and \#13 inhibited the proliferation of MDA-MB-231 cells with different potencies (Fig. 5A). When used at a $10 \mu \mathrm{M}$ concentration, the \#11-copper mixture was as potent as the 8-OHQ-copper mixture, inhibiting $\sim 90 \%$ of cell proliferation, while the \#12 and \#13-copper mixtures induced only 62 and 24\% inhibition, respectively (Fig. 5A). However, when a $25 \mu \mathrm{M}$ concentration was used, the copper mixtures with $\# 11$, \#12, and \#13 were equally potent by inducing $90 \%$ inhibition, while the copper mixtures with analogs \#10 and \#16 induced only 20 and $30 \%$ inhibition, respectively (Fig. 5A). Therefore, the position of the methyl group in the 8-OHQ analogs \#11, \#12, and \#13 affects the growthinhibitory potential of their copper mixtures. We also tested the anti-proliferative effect of the analogs alone and found that they had little to no effect on proliferation of MDA-MB231 cells (data not shown). 
A

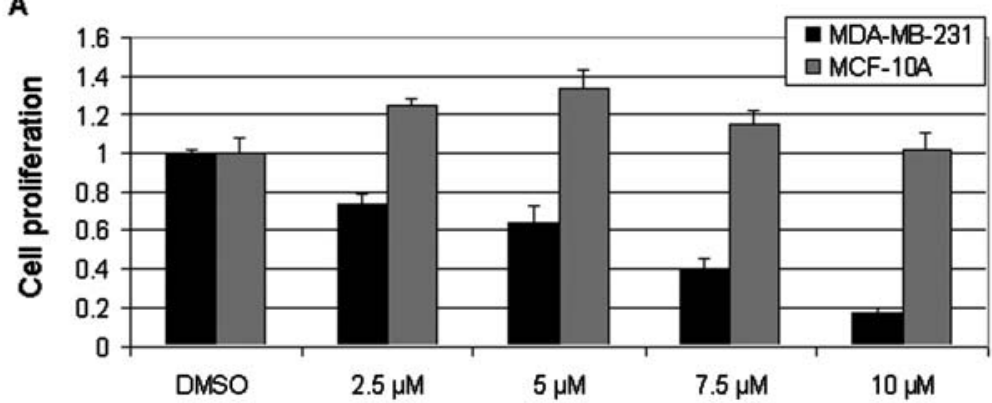

B

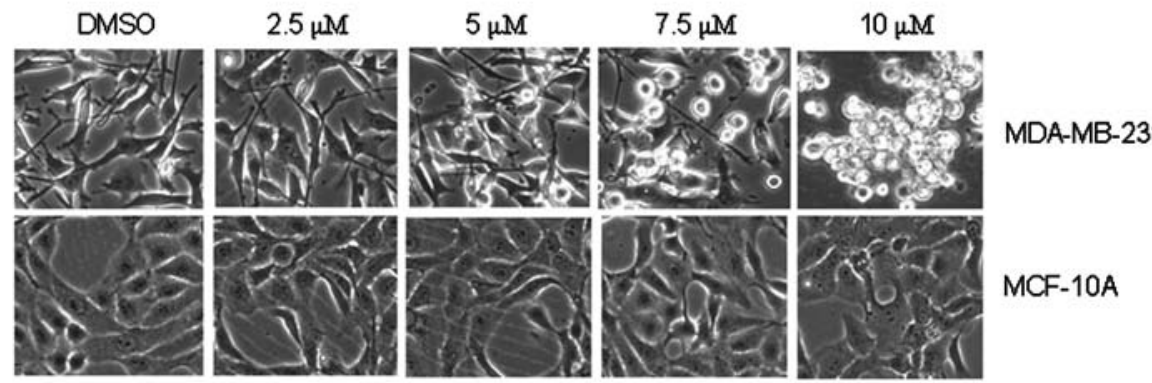

C

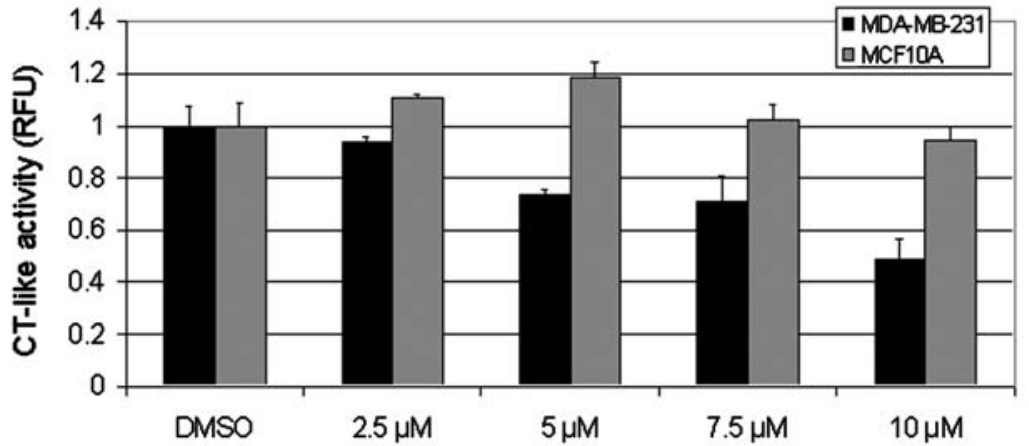

Figure 6. Differential effects of synthetic compound S13-Cu on breast cancer MDA-MB-231 cells and non-tumorigenic breast epithelial MCF-10A cells. Breast cancer MDA-MB-231 cells and immortalized but not tumorigenic MCF-10A cells were treated with 2.5 to $10 \mu \mathrm{M}$ of S13-Cu for $24 \mathrm{~h}$, followed by MTT assay (A), assessment of morphological changes (B), and measurement of proteasomal chymotrypsin (CT)-like activity (C). DMSO was used as a solvent control.

We then investigated the ability of these three mixtures to inhibit cellular $26 \mathrm{~S}$ proteasome, using copper mixtures with analogs \#10 and \#16 as controls. We treated breast cancer MDA-MB-231 cells with each mixture at a $10 \mu \mathrm{M}$ concentration for 4 and $24 \mathrm{~h}$, followed by measurement of proteasome inhibition and apoptotic cell death by multiple assays. Consistent with their anti-proliferative activities (Fig. 5A), the \#11-Cu mixture was found to be most potent, by inducing $50 \%$ of proteasomal inhibition after $4 \mathrm{~h}$ of treatment (Fig. 5B). Also at $4 \mathrm{~h}$, the analog \#12-Cu mixture had a weaker effect by inhibiting $30 \%$ of the proteasome, while the $\# 13-\mathrm{Cu}$ mixture did not cause any inhibition (Fig. 5B). After a $24 \mathrm{~h}$ treatment, the \#11-Cu mixture was as potent as 8-OHQ-copper by inducing $>90 \%$ inhibition, while the \#12-Cu mixture induced only $45 \%$ inhibition and the $\# 13-\mathrm{Cu}$ mixture had no effect (Fig. 5B). As controls, the copper mixtures with analogs \#10 and \#16 did not affect proteasomal activity at both time points (Fig. 5B). Western blot analysis showed accumulation of ubiquitinated proteins and ubiquitinated
IкB- $\alpha$ (Fig. 5C, arrow) mainly in the cells treated with the \#11-Cu (4 and $24 \mathrm{~h}$ ), \#12-Cu (mainly $24 \mathrm{~h}$ ) and 8-OHQ-Cu ( 4 and $24 \mathrm{~h}$ ) mixtures. Moreover, at $4 \mathrm{~h}$, accumulation of p21/Bax and p36/Bax was found in the order: \#11-Cu > \#12$\mathrm{Cu}>\# 13-\mathrm{Cu}$, \#10-Cu, \#16-Cu, with 8-OHQ-Cu as a positive control (all the Bax in p36/Bax form) (Fig. 5C). At $24 \mathrm{~h}$, the levels of p36/Bax were detected in the order: 8-OHQ-Cu, $\# 11-\mathrm{Cu}>\# 12-\mathrm{Cu}>\# 13-\mathrm{Cu}, \# 10-\mathrm{Cu}, \# 16-\mathrm{Cu}$, and the levels of p21/ Bax were in the order: \#12-Cu > \#13-Cu, \#10-Cu, \#16-Cu (Fig. 5C).

In the same experiment, apoptotic morphological changes were detected mainly in the cells treated with copper mixtures with analog \#11 and 8-OHQ at both 4 and 24 h (Fig. 5D). Some changes were also detected after $24 \mathrm{~h}$ treatment with \#12-Cu, but not with the others (Fig. 5D). Morphological changes and Bax accumulation were accompanied by the disappearance of full-length PARP and accumulation of the p65 cleaved PARP fragment, particularly after $24 \mathrm{~h}$ treatment, in the order: \#11-Cu $>\# 12-\mathrm{Cu}>\# 13-\mathrm{Cu}$ (Fig. 5C). Our 
results demonstrated that the rank of the copper-dependent, proteasome-inhibitory and cell death-inducing activities of these 8 -OHQ analogs is \#11 >\#12 >\#13.

Synthetic copper complex of 8-OHQ analog \#13, S13-Cu, selectively inhibits the proteasome activity and induces apoptosis in human breast cancer but not in non-malignant cells. It has been shown that various proteasome inhibitors are able to selectively induce apoptosis in human tumors but not in normal cells (21). To test whether the synthetic copper complex S13-Cu also acts in a tumor-selective manner, we plated human breast cancer MDA-MB-231 cells and human breast tissue-derived MCF-10A (immortalized but not tumorigenic) cells in a 96-well plate. The cells were allowed to attach for $24 \mathrm{~h}$ and were then treated with various concentrations of synthetic compound S13-Cu for $24 \mathrm{~h}$, followed by MTT assay. The S13-Cu treatment of MDA-MB-231 cells induced concentration-dependent inhibition of proliferation (Fig. 6A). At the lowest concentration used $(2.5 \mu \mathrm{M})$ MDAMB-231 cell proliferation was inhibited by $\sim 30 \%$, while at a $10-\mu \mathrm{M}$ concentration it induced $>80 \%$ inhibition (Fig. 6A). Inhibition of MDA-MB-231 proliferation by $\mathrm{S} 13-\mathrm{Cu}$ was accompanied by cell death-associated morphological changes, which were also dose-dependent (Fig. 6B). In sharp contrast, immortalized non-tumor MCF-10A cells appeared to be resistant since no inhibition of proliferation was found after treatment with even $10 \mu \mathrm{M}$ (Fig. 6A). Consistently, no apoptotic cells were detected in MCF-10A cells after S13-Cu treatment (Fig. 6B).

To investigate if increased sensitivity of MDA-MB-231, compared to MCF-10A cells, to $\mathrm{S} 13-\mathrm{Cu}$ treatment is caused by greater proteasome inhibition, we measured the proteasomal CT-like activity in both cell lines. We found that treatment with $\mathrm{S} 13-\mathrm{Cu}$ induced a concentration-dependent proteasomal inhibition in MDA-MB-231 cells, by inhibiting 26 and 52\% of proteasomal CT-like activity at 5- and $10 \mu \mathrm{M}$ concentrations, respectively (Fig. 6C). In contrast, treatment of MCF-10A cells with $\mathrm{S} 13-\mathrm{Cu}$ at the highest concentration used $(10 \mu \mathrm{M})$ induced $<10 \%$ inhibition of proteasomal activity. Taken together, this study demonstrated that human breast cancer MDA-MB-231 cells are much more sensitive than immortalized breast epithelial MCF-10A cells to the 8OHQ-copper-based proteasome inhibitors.

\section{Discussion}

High serum and tissue levels of copper are found in many types of human cancer including breast, prostate, colon, lung and brain, particularly in advanced and metastatic tumors (4-7). Although the mechanism for this elevation is not completely clear, a possible explanation could be that tumors accumulate high copper levels since it is necessary for their growth and metastasis.

The fact that tumors have elevated copper levels has opened a new avenue for selective anti-tumor treatment. The whole concept is to use compounds that chelate copper to cut copper supplies to tumors, thereby preventing their growth and metastasis. Animal studies that have utilized different copper chelators have shown encouraging results. For example, treatment with tetrathiomolybdate (TM), a copper chelator developed as an effective anti-copper remedy for the treatment of Wilson's disease, significantly suppressed tumor growth, associated with suppression of tumor angiogenesis (30). Similar results were obtained in clinical trials, when copper chelating by TM treatment was shown to successfully block angiogenesis. However, the TM-copper complex did not have the ability to inhibit the proteasome and failed to kill cultured cancer cells (31).

In search for potentially improved anti-copper drugs, we focused on heterocyclic nitrogen compounds. These copperbinding compounds, including 8-OHQ and its halogenated derivative clioquinol (CQ), have a wide range of bioactivities. We previously found that 8-OHQ is able to react with copper forming a complex with proteasome-inhibitory activity that suppresses proliferation and induces apoptosis in cultured breast and prostate cancer cells $(22,23)$. We also reported that after mixing solutions of $\mathrm{CQ}$ and $\mathrm{CuCl}_{2}$ at a 1:1 molar ratio, a new CQ-Cu complex was formed, as confirmed by X-ray absorption near-edge spectroscopy (XANES) and extended $\mathrm{X}$-ray absorption fine structure spectroscopy (EXAFS) (31). This CQ-Cu complex was found to inhibit the proteasome and induce apoptosis in cultured human prostate cancer cells. Consistent with previous findings that cultured cancer cells have low copper levels (26), treatment with CQ alone did not have any effect. However, when CQ alone was used for treatment of prostate cancer cells cultured in copper-enriched medium (which increased the copper level in these cells), proteasome inhibition and apoptosis were detected (31). More importantly, CQ treatment of mice bearing human C4-2B xenografts for 30 days resulted in significant inhibition of tumor growth $(66 \%)$ caused by proteasome inhibition and apoptosis induction, which was associated with inhibition of angiogenesis (31). These findings support the concept that selectively targeting elevated tumor copper leads to apoptotic cell death in vivo.

Due to their bioactivity, heterocyclic nitrogen compounds have been widely used in the pharmaceutical industry and medicine. For example, 8-OHQ is known as an antiseptic agent with mild fungistatic, bacteriostatic, anthelmintic, and amebicidal action. Various 8-OHQ derivatives were found to inhibit various enzymes, and halogenated derivatives of 8-OHQ, such as CQ, are used as topical anti-infective agents, intestinal anti-amebic and vaginal trichomonacide. The CQ oral preparation was suggested to cause subacute myelo-optic neuropathy (SMON). This conclusion was controversial and was not supported by the subsequent epidemiologic study (32). Indeed, chronic CQ treatment significantly reduces the S-adenosylmethionine (SAM) level and vitamin $B_{12}$ uptake in the brain that might contribute to the development of SMON (32). The exact mechanism is yet unknown and needs further investigation.

It has been previously shown that introduction of a hydrophilic thiocarbonyl side chain at the $\mathrm{C}_{2}$ position of the quinoline moiety provides a plausible environment for the synthesis of a compound with a ligand to copper ratio 1:1 (12). Introduction of this thiocarbonyl group upon copper complexation was proposed to lead to generation of a potent anti-cancer agent with proteasome-inhibitory activity (12). In an attempt to discover novel copper-binding, anti-cancer agents with better selectivity, we synthesized novel 8-OHQ 
analogs and their copper complexes, compared their proteasome-inhibitory activities and studied their growthinhibitory effects.

It has been shown that pharmacophores with amino groups could be easily attached to the quinoline scaffold with a formyl/acetyl group next to heterocyclic nitrogen to yield a Schiff base that could react with a variety of transition metals, including copper (33). In this study, we synthesized seven novel 8-OHQ analogs with substitutions made to the 8-hydroxyl group and investigated their copper mixtures for structure-activity relationships. We determined that the polarity of the substituents used for synthesis of these 8-OHQ analogs is important for their ability to bind copper and form complexes with anti-proliferative, proteasome-inhibitory and apoptosis-inducing abilities. When the hydroxyl group of 8-OHQ was substituted with N-phenylacetamide at the 2position (analog \#10), the potency of its copper mixture dramatically decreased. When an electron-withdrawing chlorine was attached to the phenyl ring on the N-phenylacetamide substituents (analogs \#14-\#16), their copper mixtures were also not active. However, when an electrondonating methyl group was attached to the phenyl ring on the N-phenylacetamide substituent (analogs \#11-\#13), the activities of 8-OHQ were largely intact. From these observations we concluded that an electron-donating group on the phenyl ring of the N-phenylacetamide substituent is required for the antiproliferative activity. We also showed that the position of the methyl group is important for the potencies of the synthetic ligands to bind copper and form complexes that are able to inhibit the proteasome and induce apoptosis in cancer cells. The para position seemed to generate the most potent ligand. The fact that copper complexes with analogs \#12 and \#13 (with meta or ortho methyl groups, respectively) are less potent than analog \#11 (with methyl group in para position) suggests possible steric interference that could affect copper complex formation.

As a proof of concept, we also synthesized three copper compounds using analogs \#10,\#13 and \#16 and revealed that their proteasome-inhibitory activities are comparable to their corresponding mixtures. The most potent of them, S13-Cu was then selected for testing against the breast cancer versus immortalized breast epithelial MCF-10A (non-tumorigenic) cells. We found that breast cancer MDA-MB-231 cells were much more sensitive to the $\mathrm{S} 13-\mathrm{Cu}$ treatment, compared to MCF-10A cells, consistent with what was previously proposed and shown $(21,22,31)$. Different sensitivity to the proteasome inhibition could be explained by the fact that cancer cells, due to their accelerated proliferation, depend more heavily on proteasomal activity, allowing proteasome inhibitors to discriminate between cancer and normal cells. Since the proteasome inhibitors described here are formed between 8-OHQ analogs and copper, and the copper level is elevated in many types of cancer, treatment with these analogs should provide another level of selectivity between cancer and normal cells. Furthermore, by chelating copper, these analogs should also deprive tumors of copper, thereby preventing their metastasis. However, this needs to be further tested in animal models.

In conclusion, the data presented here support the novel concept of using accumulated copper in human cancer cells as a selective approach for chemotherapy. The non-toxic copperbinding ligands such as the 8-OHQ analogs \#11-\#13, when mixed with copper, possess tumor proteasome-inhibitory and apoptosis-inducing abilities. Our study strongly suggests that cancer cells and tissues, which contain elevated copper and are dependent on proteasome activity for their survival, should be sensitive to treatment with anti-copper drugs such as the novel 8-OHQ analogs described here.

\section{Acknowledgements}

We thank Dr Fred Miller for providing the MCF-10A cell line and Ms. Carol Maconochie for reading and editing this manuscript. The study was supported by the Karmanos Cancer Institute of Wayne State University (to Q.P. Dou), Department of Defense Breast Cancer Research Program Awards (W81XWH-04-1-0688 and DAMD17-03-1-0175 to Q.P. Dou), National Cancer Institute Grant (1R01CA120009 to Q.P. Dou), and the NCI/NIH Cancer Center Support Grant (to Karmanos Cancer Institute).

\section{References}

1. Labbe $S$ and Thiele DJ: Pipes and wiring: the regulation of copper uptake and distribution in yeast. Trends Microbiol 7: 500-505, 1999.

2. Andreini C, Banci L, Bertini I and Rosato A: Zinc through the three domains of life. J Proteome Res 5: 3173-3178, 2006.

3. Maverakis E, Fung MA, Lynch PJ, Draznin M, Michael DJ, Ruben B and Fazel N: Acrodermatitis enteropathica and an overview of zinc metabolism. J Am Acad Dermatol 56: 116-124, 2007.

4. Geraki K, Farguharson MJ and Bradley DA: Concentrations of $\mathrm{Fe}, \mathrm{Cu}$ and $\mathrm{Zn}$ in breast tissue: a synchrotron XRF study. Phys Med Biol 47: 2327-2339, 2002.

5. Nayak SB, Bhat VR, Upadhyay D and Udupa SL: Copper and ceruloplasmin status in serum of prostate and colon cancer patients. Indian J Physiol Pharmacol 47: 108-110, 2003.

6. Diez M, Arroyo M, Cerdan FJ, Munoz M, Martin MA and Balibrea JL: Serum and tissue trace metal levels in lung cancer. Oncology 46: 230-234, 1989.

7. Yoshida D, Ikeda Y and Nakazawa S: Quantitative analysis of copper, zinc and copper/zinc ratio in selected human brain tumors. J Neurooncol 16: 109-115, 1993.

8. Gupta SK, Shukla VK, Vaidya MP, Roy SK and Gupta S: Serum trace elements and $\mathrm{Cu} / \mathrm{Zn}$ ratio in breast cancer patients. J Surg Oncol 46: 178-181, 1991.

9. Eatock MM, Schatzlein A and Kaye SB: Tumour vasculature as a target for anticancer therapy. Cancer Treat Rev 26: 191-204, 2000.

10. Fox SB, Gasparini G and Harris AL: Angiogenesis: pathological, prognostic, and growth-factor pathways and their link to trial design and anticancer drugs. Lancet Oncol 2: 278-289, 2001.

11. Brewer GJ: Copper control as an antiangiogenic anticancer therapy: lessons from treating Wilson's disease. Exp Biol Med 226: 665-673, 2001.

12. Adsule S, Barve V, Chen D, Ahmed F, Dou QP, Padhye S and Sarkar FH: Novel Schiff base copper complexes of quinoline-2 carboxaldehyde as proteasome inhibitors in human prostate cancer cells. J Med Chem 49: 7242-7246, 2006.

13. Orlowski RZ and Dees EC: Applying drugs that affect the ubiquitin-proteasome pathway to the therapy of breast cancer. Breast Cancer Res 5: 1-7, 2003.

14. Landis-Piwowar KR, Milacic V, Chen C, Yang H, Zhao Y, Chan TH, Yan B and Dou QP: The proteasome as a potential target for novel anticancer drugs and chemosensitizers. Drug Resist Updat 9: 263-273, 2006.

15. Ciechanover A: The ubiquitin-proteasome pathway: on protein death and cell life. EMBO J 17: 7151-7160, 1998.

16. Seemuller E, Lupas A, Stock D, Lowe J, Huber R and Baumeister W: Proteasome from thermoplasma acidophilum: a threonine protease. Science 268: 579-582, 1995. 
17. An B, Goldfarb RH, Siman R and Dou QP: Novel dipeptidyl proteasome inhibitors overcome $\mathrm{Bcl}-2$ protective function and selectively accumulate the cyclin-dependent kinase inhibitor p27 and induce apoptosis in transformed, but not normal, human fibroblasts. Cell Death Differ 5: 1062-1075, 1998.

18. Lopes UG, Erhardt P, Yao R and Cooper GM: p53-dependent induction of apoptosis by proteasome inhibitors. J Biol Chem 272: 12893-12896, 1997.

19. Adams J: Potential for proteasome inhibition in the treatment of cancer. Drug Discov Today 8: 307-315, 2003.

20. Almond JB and Cohen GM: The proteasome: a novel target for cancer chemotherapy. Leukemia 16: 433-443, 2002.

21. Dou QP and Li B: Proteasome inhibitors as potential novel anticancer agents. Drug Resist Update 2: 215-223, 1999.

22. Daniel KG, Chen D, Orlu S, Cui QC, Miller FR and Dou QP Clioquinol and pyrrolidine dithiocarbamate complex with copper to form proteasome inhibitors and apoptosis inducers in human breast cancer cells. Breast Cancer Res 7: R897-R908, 2005.

23. Chen D, Peng F, Cui QC, Daniel KG, Orlu S, Liu J and Dou QP: Inhibition of prostate cancer cellular proteasome activity by a pyrrolidine dithiocarbamate-copper complex is associated with suppression of proliferation and induction of apoptosis. Front Biosci 10: 2932-2939, 2005.

24. Chen D, Daniel KG, Chen MS, Kuhn DJ, Landis-Piwowar KR and Dou QP: Dietary flavonoids as proteasome inhibitors and apoptosis inducers in human leukemia cells. Biochem Pharmacol 69: 1421-1432, 2005.

25. Milacic V, Chen D, Ronconi L, Landis-Piwowar KR, Fregona D and Dou QP: A novel anticancer gold(III) dithiocarbamate compound inhibits the activity of a purified 20S proteasome and $26 \mathrm{~S}$ proteasome in human breast cancer cell cultures and xenografts. Cancer Res 66: 10478-10486, 2006.
26. Daniel KG, Gupta P, Harbach RH, Guida WC and Dou QP: Organic copper complexes as a new class of proteasome inhibitors and apoptosis inducers in human cancer cells. Biochem Pharmacol 67: 1139-1151, 2004.

27. Pink JJ, Wuerzberger-Davis S, Tagliarino C, Planchon SM, Yang X, Froelich CJ and Boothman DA: Activation of a cysteine protease in MCF-7 and T47D breast cancer cells during ß-Lapachone-mediated apoptosis. Exp Cell Res 255: 144-155, 2000 .

28. Gao G and Dou QP: N-terminal cleavage of Bax by calpain generates a potent proapoptotic $18-\mathrm{kDa}$ fragment that promotes $\mathrm{Bcl}-2$-independent cytochrome $\mathrm{C}$ release and apoptotic cell death. J Cell Biochem 80: 53-72, 2000.

29. Wood DE and Newcomb EW: Cleavage of Bax enhances its cell death function. Exp Cell Res 256: 375-382, 2000.

30. Pan Q, Bao LW and Merajver SD: Tetrathiomolybdate inhibits angiogenesis and metastasis through suppression of the NFKB signaling cascade. Mol Cancer Res 1: 701-706, 2003.

31. Chen D, Cui QC, Yang H and Dou QP: Disulfiram, a clinically used anti-alcoholism drug and copper-binding agent, induces apoptotic cell death in breast cancer cultures and xenografts via inhibition of the proteasome activity. Cancer Res 66: 10425-10433, 2006.

32. Yassin MS, Ekblom J, Xilinas M, Gottfries CG and Oreland L: Changes in uptake of vitamin $\mathrm{B}(12)$ and trace metals in brains of mice treated with clioquinol. J Neurol Sci 173: 40-44, 2000.

33. El-Sonbati AZ, Al-Shihri AS and El-Bindary AA: Stereochemistry of new nitrogen containing heterocyclic aldehyde. Part XI. Novel ligational behaviour of quinoline as chelate ligand toward transition metal ions. Spectrochim Acta A Mol Biomol Spectrose 60: 1763-1768, 2004 